\title{
Shell Thinning Phenomena Affected by Heat Transfer, Nozzle Design and Flux Chemistry in Billets Moulds
}

\author{
Alfonso NAJERA-BASTIDA, ${ }^{1)}$ Rodolfo D. MORALES, ${ }^{2)}$ S. GARCIA-HERNANDEZ, ${ }^{1)}$ \\ Enrique TORRES-ALONSO ${ }^{11}$ and Aron ESPINO-ZARATE ${ }^{11}$
}

1) Graduate Students, Department of Metallurgy and Materials Engineering, National Polytechnic Institute-ESIQIE, Apdo. Postal 75-874, México, D.F. E-mail: alfonso_najera@yahoo.com.mx, iq_sagahz@hotmail.com

2) Department of Metallurgy and Materials Engineering, National Polytechnic Institute-ESIQIE, Apdo, Postal 75-874, México

D.F. and K\&E Technologies President. E-mail: rmorales@ipn.mx, ketechnologies@prodigy.net.mx

(Received on October 16, 2009; accepted on March 8, 2010)

\begin{abstract}
Shell thinning affected by nozzle design, flux chemistry, heat transfer and steel flow was simulated through a mathematical model. Two nozzles were studied, the first, S60 with outer and inner diameters of $60 \mathrm{~mm}$ and $36 \mathrm{~mm}$ and the second, S73, with outer and inner diameters of $73 \mathrm{~mm}$ and $36 \mathrm{~mm}$, respectively. Casting conditions include a casting speed of $1.3 \mathrm{~m} / \mathrm{min}$, use of a basic flux and a superheat of $36 \mathrm{~K}$. Simulations included hypothetical isothermal casting conditions compared with casting conditions under thermal gradients. Simulation results indicated that the buoyancy forces, generated by thermal fields, exert a braking effect on the discharging jet whose magnitude was approximately $1 / 4$ of the inertial forces. Shell growth along the curved mould walls suffers considerably thinning effects through the transport of sensible heat by convective mechanisms. Both nozzles induce shell thinning although, predictions of this mathematical model, using nozzle S73, indicate severe shell thinning effects in a region located in the inner radius side, down the second half of the mould length. This final shell thickness is very small making possible the existence of a strand breakout. Steel solidification along the flat mould walls leads to thick and uniform shells using either of these nozzles. The present numerical results indicate that in the field of flux design steel chemistry must be taken into account together with nozzle design.
\end{abstract}

KEY WORDS: billet; flux infiltration; shell growth; shell thinning; fluid flow; heat transfer.

\section{Introduction}

Shell thinning of steel in continuous casting of billets moulds may eventually lead to strand breakouts so harmful to caster productivity and plant integrity. Given the complex flow structure and the magnitudes of liquid superheat in billet moulds, shell growth can be hindered through convection mechanisms inducing to thinning effects in the strand. Nozzle design and its immersion position have a direct influence on shell thinning by the manipulation of the flow pattern of steel inside the mould. Moreover, mould flux chemistry influences also considerably shell thickness since its thermo-physical properties influence heat transfer rates by its infiltrating characteristics through the mouldstrand gap. Regarding heat transfer in the mould there are reported many works; however, most of them isolate these transport phenomena from fluid flow dynamics and flux chemistry effects. ${ }^{1-4)}$ Usually, a heat flux boundary condition is applied in the mould faces using an empirical heat transfer profile reported by Savage and Pritchard. ${ }^{5)}$ Other works have been focused on fluid dynamics aspects inside billet moulds using physical models and/or mathematical simulations visualizing the presence of highly recirculating flows induced by the confined spaces in billet moulds. ${ }^{6-9)}$ Thermal aspects have been studied by Chow and Sama- rasekera $^{10)}$ and Chow et al. ${ }^{11)}$ who found that heat flux peaks are 2.5 times higher for casting with speeds of 3.4$4.5 \mathrm{~m} / \mathrm{min}$ than in the case of conventional casting speeds such as $2.5-3.0 \mathrm{~m} / \mathrm{min}$. Compared with oil lubrication, mould powders decrease heat flux and make a uniform heat extraction throughout the mould faces. Since mould powders are very important, there is a prolific production of scientific literature related with their complex role on heat flux and lubrication phenomena between the mould and the strand. The important physical-chemical characteristics of powders are the melting point, viscosity-temperature relationship, breaking or melting temperature, solidus temperature, density, melting rate and thermal conductivity all dependent on their chemical composition. Indeed, Kawamoto et al. ${ }^{12)}$ reported that in order to prevent longitudinal cracking it was recommended to use a mould powder with high solidification temperatures where crystallization of cuspidine $\left(\mathrm{Ca}_{4} \mathrm{~F}_{2} \mathrm{Si}_{2} \mathrm{O}_{7}\right)$ occur. Therefore, for casting low carbon and peritectic steels, precipitation of cuspidine favors slower cooling rates at the meniscus. Cho et al. ${ }^{13-15)}$ corroborated those views claiming that slow cooling is required for casting surface-cracking sensitive medium carbon-peritectic steels, using basic mould powders with high crystallization rates.

Efforts have been made also by using the thermal data 
of mould powders to simulate their effects on heat flux through the mould estimating the flux film thickness in the mould-strand gap. Following this line of research, Yamauchi et al. ${ }^{16)}$ reported an analytical solution of the NavierStokes equations to define the lubricating-laminar velocity profile of liquid flux and its interaction with the strand and the solid flux. Using their model these authors calculated the flux film thickness along the mould and estimated the changes of pressure gradients in the gap as function of one mould oscillation cycle. Okazawa et $a l .{ }^{17,18)}$ reported steady and unsteady mathematical models solving the laminarReynolds equation for flux film infiltration through the gap between the strand and the mould. According with these authors mould powder can be infiltrated because the cyclic motion of the shell lags that of the mould oscillation. This provides a period when the mould-strand gap opens during the downwards motion of the mould. It is during this period when molten powder or flux is infiltrated down the channel or gap.

In all those works, continuous growth of the shell downstream the mould is predicted, while the effects of fluid flow and nozzle design are not considered. Few attempts have been carried out taking into consideration the effects of fluid flow of steel inside the mould. Some authors had reported that, fluid flow is capable of thinning the shell due to convection effects transporting metal superheat. ${ }^{19,20)}$ Thomas et l. $^{21)}$ simulated heat transfer and fluid flow for a slab mould where, in order to avoid the employment of an empirical boundary condition in the mould faces for heat flux, assumed a constant mould hot face temperature. Although shell thinning effects could be predicted, as influenced by convection of steel superheat, this approach neglects the effects of flux chemistry. Different to that work, the group of the authors ${ }^{22,23)}$ simulated shell thinning in a slab mould using the combined effects of the main thermophysical properties of the mould powder, steel superheat and fluid flow patterns of steel. This later factor is of extreme importance since, as the authors have demonstrated, steel flows dynamics in billet moulds are actually very complex and interact closely with mould flux. ${ }^{24)}$

The objectives and aims of the present work consist of the development of a mathematical model for steel solidification which includes the effects of nozzle design influencing, fluid flow patterns, mould powder chemistry and heat transfer. This model is applied to simulate shell growth dynamics and shell thinning effects affected by casting variables. For pursuing those objectives a theoretical approach is used using published results of heat transfer profiles through the mould walls. It is important to remark that the isothermal results, about to be presented here, have been already modeled physically and mathematically and its validation has been published in a previous work. ${ }^{24)}$

\section{Mathematical Model}

\subsection{Fluid and Turbulence Model}

The fluid model is based on the solution of the NavierStokes equations for incompressible viscous flow. The focus of the present study is the heat transfer and solidification effects inside the billet mould. Therefore, the turbulence model was kept as simple as possible without affect- ing the overall solution. The $k-\varepsilon$ model has been proven to give acceptable results in prior works ${ }^{25}$ and it is used here to save computing time. The fundamentals of NavierStokes and the $k-\varepsilon$ equations can be found in different publications. $^{21-23,26)}$

\subsection{Multiphase Model}

The Volume of Fluid (VOF) model was employed to solve the multiphase system air-steel-slag. This scheme performs the calculation of the interface between the phases ( $p$ and $q$ ) present at each cell, based on their fraction as shown $^{27,28)}$ below (see nomenclature at the end of this paper);

$$
\begin{aligned}
& \rho_{\text {mix }}=\alpha_{\rho} \rho_{\rho}+\left(1-\alpha_{q}\right) \rho_{\rho} \\
& \mu_{\text {mix }}=\alpha_{\rho} \mu_{\rho}+\left(1-\alpha_{q}\right) \mu_{\rho}
\end{aligned}
$$

A unique continuity equation for the transient system is derived depending on the number of phases; therefore, the Eq. (3) is divided by the amount of phase $q$ in the cell. Mass exchange between phases can be modelled by introducing an additional source term $\left(S_{\alpha_{q}}\right)$.

$$
\frac{\partial}{\partial t}\left(\alpha_{q} \rho_{q}\right)+\nabla \cdot\left(\alpha_{q} \rho_{q} \vec{v}\right)=S_{\alpha_{q}}+\sum_{p=1}^{n}\left(\dot{m}_{p q}-\dot{m}_{q p}\right)
$$

The VOF model solves a single set of momentum transfer equations when two or more phases coexist in the cell.

$$
\begin{aligned}
& \frac{\partial}{\partial t}\left(\rho_{\text {mix }} \vec{v}\right)+\nabla \cdot\left(\rho_{\text {mix }} \vec{v} \vec{v}\right) \\
& \quad=-\nabla p+\nabla\left[\mu_{\text {mix }}(\nabla \vec{v}+\nabla \vec{u})\right]+\rho_{\text {mix }} \beta \Delta T g-S_{s}+S_{\sigma}
\end{aligned}
$$

The third term in the right hand side of this multiphase momentum transfer equation is the buoyancy forces provided by thermal gradients in steel. The tracking of the interface is accomplished by an implicit method, which solves the face fluxes $(\dot{m})$ in each grid cell through Eq. (5).

$$
\begin{aligned}
& \frac{\alpha_{q}^{n+1} \rho_{q}^{n+1}-\alpha_{q}^{n} \rho_{q}^{n}}{\partial t} V+\sum_{f}\left(\rho_{q}^{n+1} U_{f}^{n+1} \alpha_{q, f}^{n+1}\right) \\
& =\left[S_{\alpha q}+\sum_{p=1}^{n}\left(\dot{m}_{p q}-\dot{m}_{q p}\right)\right] V \text {. }
\end{aligned}
$$

As the previous equation requires the volume fraction values of the actual time step, an additional scalar transport equation for the steel and slag is solved iteratively at each time step for the transient state. Momentum transfer equations were solved using appropriate boundary conditions such as no-slip condition for all surfaces, a velocity distribution inside the nozzle that obeys the $1 / 7$ law, ${ }^{29)}$ a kinetic energy in nozzle tip defined by the velocity distribution. In the viscous sublayer the high velocity gradients were connected with the main flow through the logarithmic law ${ }^{30}$ ) and the turbulent viscosity was calculated through the relationship $\rho C_{\mu} k^{2} / \varepsilon$. 


\subsection{Heat Transfer Model}

The steel, slag and air share the energy equation which is written as follows.

$$
\frac{\partial}{\partial t}(\rho E)+\nabla \cdot(\vec{v}(\rho E+p))=\nabla \cdot\left(K_{q} \nabla T\right)
$$

For the top mould, bottom mould and the cold face the next boundary condition is considered.

$$
-k(T) \frac{\partial T}{\partial y}=0
$$

For the hot face of the mould the next boundary condition is considered: The heat flux to the mould walls was considered as a function of the mould length and it was constant in all walls. This function was obtained from instrumented moulds as reported by ${ }^{31)}$ which includes the air and steel zones. This heat flux profile was adjusted by curve fitting techniques according to:

$$
\begin{aligned}
& -k(T) \frac{\partial T}{\partial y}=-86414027.18 y^{4}+103868121.34 y^{3} \\
& -37597994.70 y^{2}+5027814.05 y \\
& +725571.18
\end{aligned}
$$

\subsection{Solidification Model}

The solidification profile is calculated for the slag or the steel phase $(p, q)$ based on an enthalpy method where the liquid fraction is calculated by:

$$
f_{l}=\frac{T_{q}-T_{q, \text { solidus }}}{T_{q, \text { liquidus }}-T_{q, \text { solidus }}}
$$

The heat transfer is modified by the latent heat evolution of the steel and slag during solidification in their respective mushy zones. The temperature variation as a function of the effective thermal conductivity of the phase in question is calculated by:

$$
\frac{\partial}{\partial t}\left(\rho_{q} E\right)+\nabla \cdot\left(\rho_{q} \vec{v} E\right)=\nabla \cdot\left(K_{q} \nabla T\right)
$$

An enthalpy-porosity technique, that treats the mushy zone as a porous medium, is used to include the velocity sink resulting from the solidification. This sink term reduces the velocity depending on the solidification fraction at each cell as show in Eq. (11).

$$
S_{s}=\frac{\left(1-f_{l}\right)^{2}}{\left(0.001+f_{l}^{2}\right)} A_{\mathrm{mush}}\left(\vec{v}-v_{c}\right)
$$

\subsection{Model Description}

A numerical model based on the commercial software FLUENT $^{\circledR}$ was created for a billet mould. Figure 1 shows the dimensions of the model that includes the geometries of both nozzles and the copper mould. Figure 2 shows the computational meshes for the mould and the two nozzles, that has a total of 1500000 grid cells in a structured mesh. The inlet velocity is calculated to maintain the desired casting speed at the outlet. A pressure inlet condition is applied at the mould top $(P=101325 \mathrm{~Pa}, T=273 \mathrm{~K})$ to model the effects of a system open to the atmosphere. The slag is supplied at this boundary (as in the real process) by calculating the mass of slag required for good casting practice. To calculate mould flux consumption there are many empirical correlations based on analysis of plant data such as those determined by Kwon et al., ${ }^{32)}$ Nakajima et al. ${ }^{33)}$ and Wolf ${ }^{34)}$ for slabs and blooms, but the most recommendable for billet casters is that proposed by Ogibayashi ${ }^{35)}$ which is as follows;

$$
Q=\frac{0.6}{\mu_{\text {flux }} v_{c}}
$$

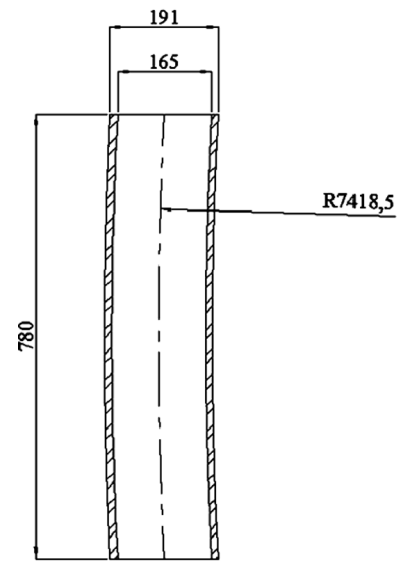

a)

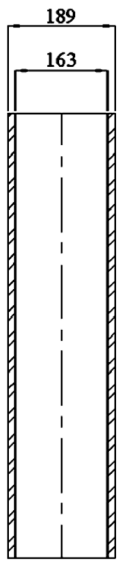

b)
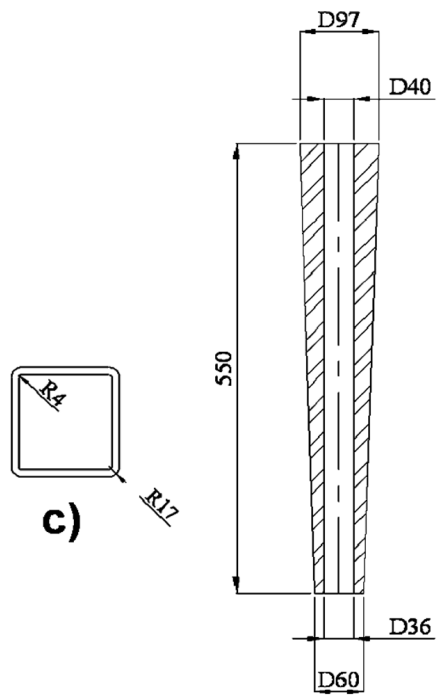

d)

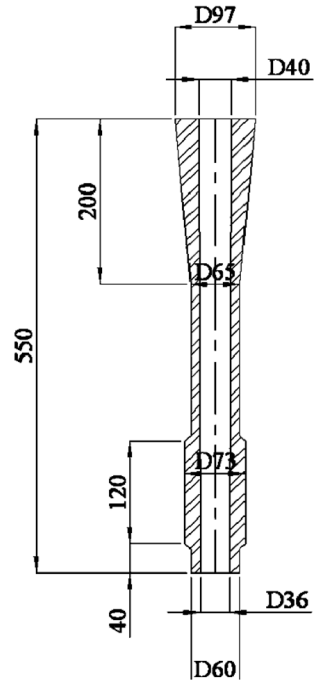

e)

Fig. 1. Geometry of mould and nozzles in mm. Billet mould: a) lateral view, b) frontal view and c) upper view; nozzle: d) S60 and e) S73. 
To calculate mould flux viscosity there are also many models such as those of Riboud, ${ }^{36)}$ Rist, ${ }^{37)}$ Koyama, ${ }^{38)}$ Urbain as is explained by Mills ${ }^{39)}$ and Iida models. ${ }^{40)}$ In this work Iida's model was employed to calculate flux viscosity.

Materials properties and the casting conditions employed on the simulations are presented in the Table $\mathbf{1}$ and Table 2. This system is initially solved under isothermal conditions until a stable flow pattern is reached after approximately $300 \mathrm{~s}$ of computational real time. Subsequently, the heat transfer in the system is solved until a uniform temperature field is obtained approximately after $100 \mathrm{~s}$ of calculation. Finally, the solidification model was activated and modelled for $180 \mathrm{~s}$. The non-lineal governing equations were solved using a segregated solver through an implicit, first order up-

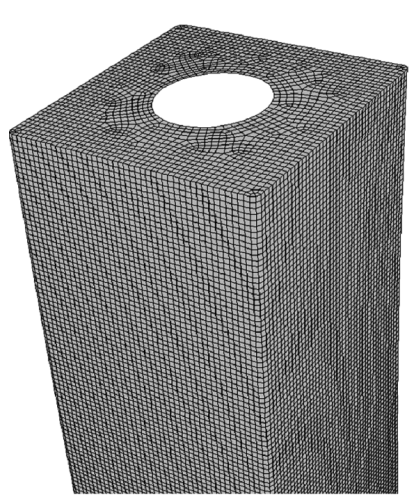

a)

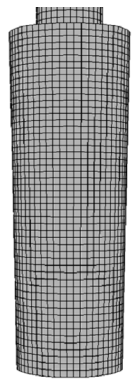

b)

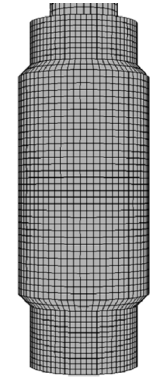

c)
Fig. 2. Computational grids: a) upper mould region, b) nozzle $\mathrm{S} 60$ and c) nozzle S73.

Table 1. Thermo-physical properties and parameters used for simulation.

\begin{tabular}{|c|c|}
\hline Parameters & Values \\
\hline Casting speed (m/min) & 1.3 \\
\hline Nozzle immersion $(m)$ & 0.9 \\
\hline Casting temperature $(\mathrm{K})$ & 1823 \\
\hline \multicolumn{2}{|l|}{ Steel properties* } \\
\hline Thermal expansion coefficient $\left(\mathrm{K}^{-1}\right)$ & 0.85358 \\
\hline Thermal conductivity $\left(\mathrm{W} \mathrm{m}^{-1} \mathrm{~K}^{-1}\right)$ & 32.7 \\
\hline Density $\left(\mathrm{kg} \mathrm{m}^{-3}\right)$ & $8586-0.8567 \mathrm{~T}$ \\
\hline Viscosity (Pa s) & 0.0064 \\
\hline Melting heat $\left(\mathrm{J} \mathrm{kg}^{-1}\right)$ & 250,000 \\
\hline Liquidus temperature $(\mathrm{K})^{\star * 42)}$ & 1787.5 \\
\hline Solidus temperature $(\mathrm{K})^{\star \star}$ & 1724 \\
\hline \multicolumn{2}{|l|}{ Air properties } \\
\hline Thermal conductivity $\left(\mathrm{W} \mathrm{m}^{-1} \mathrm{~K}^{-1}\right)$ & 0.06 \\
\hline Density $\left(\mathrm{kg} \mathrm{m}^{-3}\right)$ & 1.225 \\
\hline Viscosity ( $\mathrm{Pa} \mathrm{s}$ ) & $1.789 \times 10^{-5}$ \\
\hline \multicolumn{2}{|c|}{$\begin{array}{l}\text { *Steel chemistry in mass \%: } \mathrm{C}=0.07, \mathrm{Mn}=1.12, \mathrm{Si}=0.03, \mathrm{P}=0.05, \mathrm{~S}=0.3, \mathrm{Cr} \\
=0.15, \mathrm{Ni}=0.1, \mathrm{Mo}=0.025, \mathrm{Al}=0.003 \text { and } \mathrm{Cu}=0.22 .\end{array}$} \\
\hline \multicolumn{2}{|c|}{$\begin{array}{l}T_{\text {liquidus }}\left[{ }^{\circ} \mathrm{C}\right]=1537-88[\% \mathrm{C}]-25[\% \mathrm{~S}]-5[\% \mathrm{Mn}]-2[\% \mathrm{Mo}]-4[\% \mathrm{Ni}]-1.5[\% \mathrm{Cr}]-18[\% \mathrm{Ti}] \\
-2[\% \mathrm{~V}]-30[\% \mathrm{P}] \\
T_{\text {solidus }}\left[{ }^{\circ} \mathrm{C}\right]=1535-200[\% \mathrm{C}]-12.3[\% \mathrm{Si}]-6.8[\% \mathrm{Mn}]-124.5[\% \mathrm{P}]-183.9[\% \mathrm{~S}]-4.3[\% \mathrm{Ni}] \\
-1.4[\% \mathrm{Cr}]-4.1[\% \mathrm{Al}]\end{array}$} \\
\hline
\end{tabular}

Table 2. Chemistry and physical properties of mould flux.

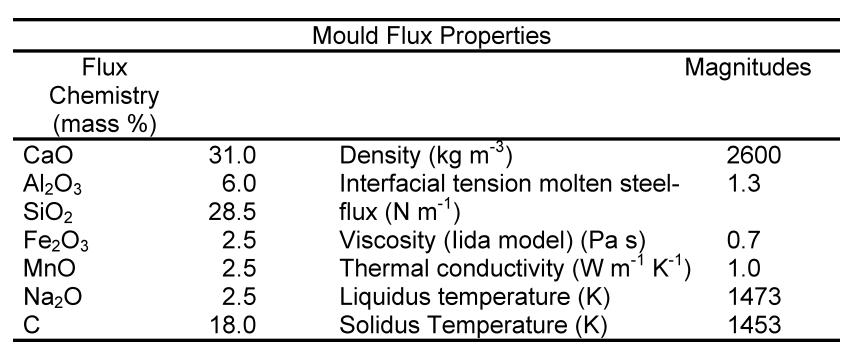

wind discretization schemes for turbulence, moment and energy parameter, and PRESTO for the pressure; the SIMPLEC algorithm was used for pressure-velocity coupling. Convergence is reached when the residuals are below $1 \times 10^{-4}$ in time steps of $0.01 \mathrm{~s}$.

\section{Results and Discussion}

Figures 3(a) and 3(b) show the velocity profiles in the central-symmetric plane parallel to the mould radius under isothermal and non-isothermal conditions for nozzle S60, respectively. It is readily apparent that the thermal field induces a considerable braking effect of the flow since the jet has a shorter penetration depth, the recirculating flow in the outer mould radius side becomes smaller and the flow in the inner mould radius yields smaller velocities than in the isothermal case due to the effects of the pulling speed or casting rate. Figures 3(c) and 3(d) show the same type of information for a flow under the effects of nozzle S73. Again a considerable flow braking effect is observed in the non-isothermal case (Fig. 3(d)) where there is an ascending flow to the bath top in the side of the inner mould radius that coincides with results previously presented in a water model. ${ }^{24)}$ A feasible explanation for the braking effects of both cases is the existence of large buoyancy forces induced by the temperature gradients and the downwards shearing stresses produced by the pulling speed or casting speed of the shell. This later effect is particularly effective along the mould walls as can be seen in Figs. 3(b) and 3(d). It is important to observe that the flow patterns, either under isothermal or non-isothermal conditions, change according to the nozzle that is being used even if the difference of geometries is actually very small (nozzles S73 has an outer protective ring against slag attack). It is also worthy to underline that the non-symmetric flows in planes parallel to the mould radius are essentially originated by the mould curvature. Figure 4 shows a close 3D view at the meniscus level of the velocity profiles in two planes, the first $0.03 \mathrm{~m}$ below the meniscus and the second at the level of the SEN tip, under isothermal (Fig. 4(a)) and non-isothermal (Fig. 4(b)) conditions for nozzle S60. The isothermal steel flow

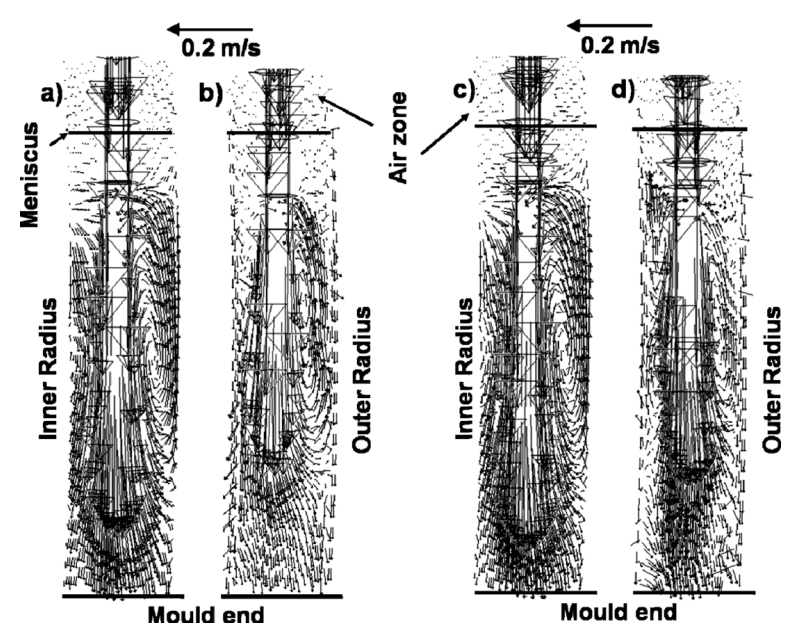

Fig. 3. Velocity vectors on the central-symmetric plane parallel to the mould radius. SEN S60: a) isothermal and b) nonisothermal; SEN S73: c) isothermal and d) non-isothermal. 
that is coming up from the outer mould radius surrounds the nozzle, at the level of its tip, and changes its trajectory to descend through the lateral regions located between the nozzle and the straight mould walls; nevertheless part of this flow continues ascending along the corners of the outer mould radius. Under temperature gradients the flow be-

a)

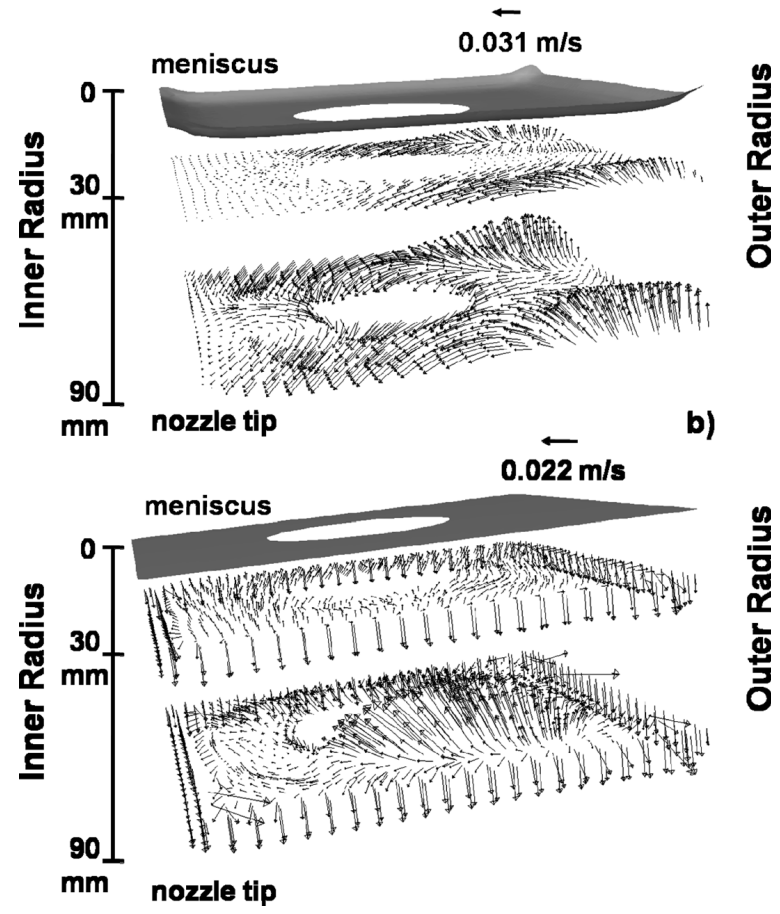

Fig. 4. A $3 \mathrm{D}$ close view of the velocity vectors on two horizontal planes for nozzle $\mathrm{S} 60$, the first at $0.03 \mathrm{~m}$ below the meniscus and the second at the level of the nozzle tip: a) isothermal and b) non-isothermal.
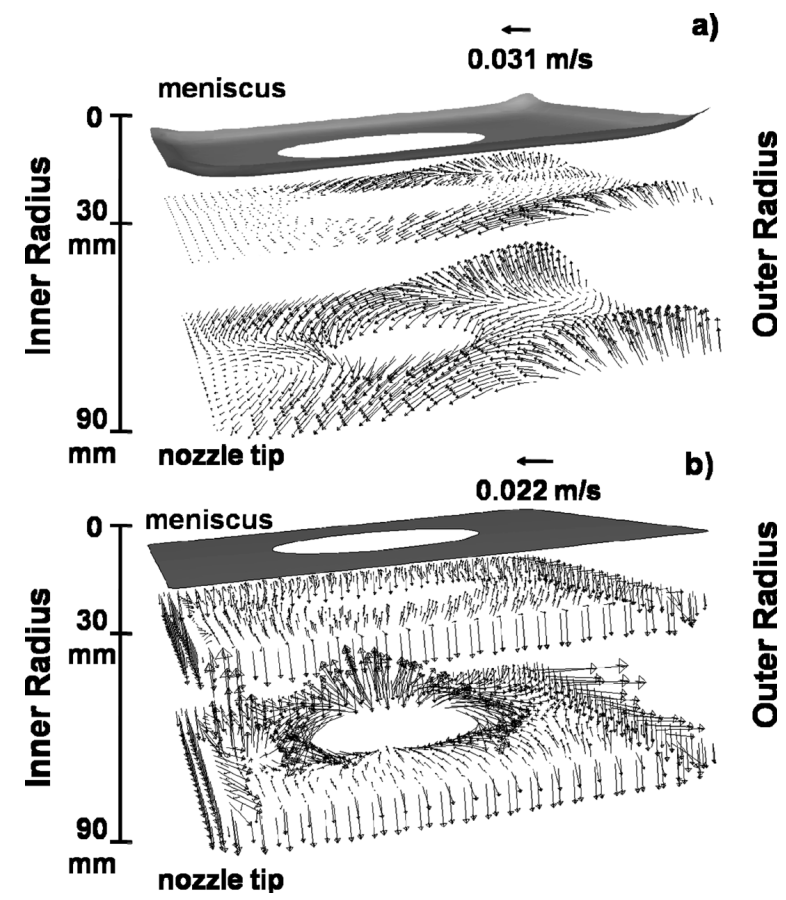

Fig. 5. A $3 \mathrm{D}$ close view of the velocity vectors on two horizontal planes for nozzle S73, the first at $0.03 \mathrm{~m}$ below the meniscus and the second at the level of the nozzle tip: a) isothermal and $\mathrm{b}$ ) non-isothermal. comes into a non-symmetric ascending flow through the gap formed by the mould and nozzle walls. The flow, which continues ascending along the outer mould radius side, later descends around the mould from the top by the effect of the pulling shell velocity. Figure 5 shows the same type of information as Fig. 4, but for a flow under the effects of nozzle S73. The first case, Fig. 5(a), is very similar to the flow described in Fig. 4(a); however, under non-isothermal conditions the flow ascends along the inner mould radius with asymmetrical patterns and larger velocities, Fig. 5(b). Comparing with Fig. 4(b), the upper plane shows larger velocities which are ascribed to the narrower gap between the nozzle and mould walls enhanced by the thermal buoyancy effects. Generally speaking these changes lead to stronger stirring conditions of the melt at meniscus level. Using a water model and PIV measurements, Torres-Alonso et al. ${ }^{24)}$ found that this narrower gap and the step of the lower ring of nozzle S-73 (see Fig. 1(e)), work synergistically to induce a channelling flow which alters the flow significantly. These authors found that the flow is strongly rotational in the gap formed between the mould and the nozzle walls. Finally, the flow, similarly to the way shown in Fig. 4(b), descends around the mould by the effect of the pull shell velocity.

To explain the effects of temperature gradients on fluid flow patterns the ratio between buoyancy and inertial forces was calculated through the following equation ${ }^{41)}$ :

$$
\frac{G r}{\operatorname{Re}^{2}}=\frac{0.85358 g \Delta T L}{\rho v^{2}}
$$

The Grashof number was calculated using as reference temperature the average between the mushy and static temperatures of steel and the results are presented in the centralsymmetric plane parallel to the mould radius in Figs. 6(a)

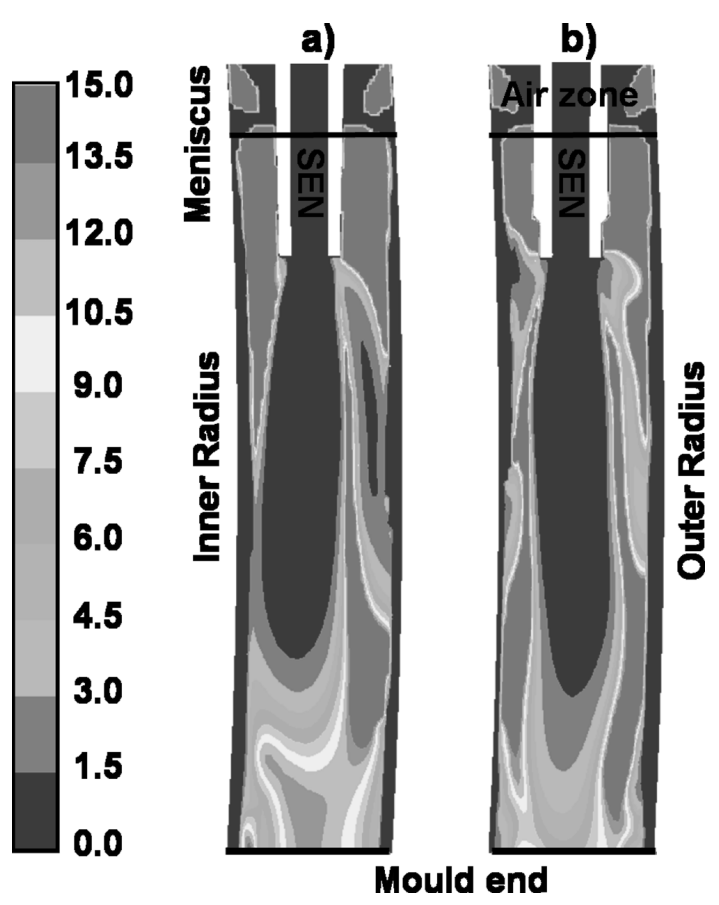

Fig. 6. Contours of the ratio between buoyancy and inertial forces on the central-symmetric plane parallel to the mould radius: a) nozzle $\mathrm{S} 60$ and b) nozzle S73. 
and 6(b) for nozzles S60 and S73, respectively. As expected, the regions corresponding to the discharging jets yield the smallest magnitudes as in those regions inertia forces dominate the momentum balance. It is also important to notice that this ratio is also very small along the mould walls due to the downward dragging stresses induced by the mushy zone on the adjacent melt flow. At the meniscus level, buoyancy forces are 15 times larger than inertial forces explaining the ascending flows presented in Figs. 4(b) and 5(b). The regions surrounding the discharging jets, showing high force ratios, are larger using nozzle S73 than using nozzle S60. For example, in the outer mould radius side, using nozzle $\mathrm{S} 73$, the regions where the force ratio is high are larger than the corresponding region of nozzle S60. Something similar can be said about the inner mould side of nozzle S73. At the mould end, nozzle S60 is apparently more affected by buoyancy forces than nozzle S73. Generally speaking, the qualitative force ratio provided by Eq. (13) is indicating that the distribution of inertial and buoyancy forces change considerably due to a very simple change of the nozzle outer geometry. In spite that the force ratio is useful information in order to understand fluid flow dynamics in this mould, it is certainly necessary to quantify these forces. For this purpose the momentum transfer along the axes of the discharging jets under isothermal conditions was calculated by the relation $\rho v v / L_{0}$. This momentum was considered as the pure inertia contribution. This procedure was repeated for the flow under non-isothermal conditions, where the momentum is already affected by the buoyancy effects. Therefore, the difference between these two forces provides the actual buoyancy force which yields braking effects to the discharging jets. These forces are plotted in Figs. 7(a) and 7(b) for nozzles S60 and S73, respectively; inertial forces, either isothermal or no-isothermal, are maximum just at the nozzles tips and decrease along the mould depth. On the other hand, the buoyancy forces are small at the nozzles tips since inertial forces

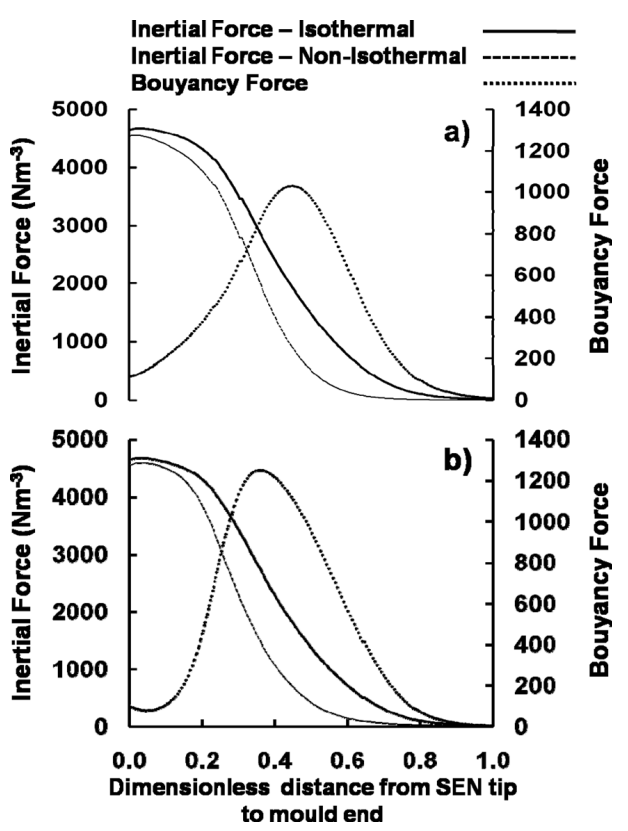

Fig. 7. Inertial and buoyancy forces along the axes of the discharging jets under isothermal and non-isothermal conditions: a) nozzle S60 and b) nozzle S73. dominate momentum transfer, reach a maximum at an intermediate distance along the mould length, and decrease depth inside the mould where inertia forces become similar to buoyancy forces. Maximum magnitudes of buoyancy forces represent, roughly speaking, about $1 / 4$ th of the magnitude of inertial forces and this explains the great braking effect of the discharging jets that is evident in Figs. 3(a)3(d).

Simulations for temperature fields and shell growth in the central-symmetric plane parallel to the mould radius using nozzles S60 and S73 are plotted in Figs. 8(a) and 8(b), respectively. As is seen, using the first nozzle yields a thick shell in the interior mould wall and shell thinning effects on the outer mould wall particularly in the second lower half of the mould height. This phenomenon has its origin in the transport of energy provided by the recirculating flow existent in that region which has relatively high velocities increasing the convection effects (see Fig. 3(b)). It is worthy to mention that once the flux infiltrates the gap between the strand and the hot mould wall, it must have a considerable influence on the shell thickness. Using nozzle S73 the shell thinning effect is now observed in the interior mould radius while in the outer mould radius side the shell grows reaching a large thickness. As is seen in Fig. 3(d), melt velocities in the shell thinning region are not large enough to explain the affectation on the growth and it is then possible to mention that the inefficiencies of flux filtration plays a very important role as will be seen later. Figure 8(b) shows the most dramatic shell thinning effects, because shell thickness is very small in the lower part of the mould in the left side of the figure to the extent that a breakout is feasible. Corresponding plots of temperature fields and shell growth in the central-symmetric plane perpendicular to the mould radius are plotted in Figs. 9(a) and 9(b) using nozzles S60 and S73, respectively. Employing

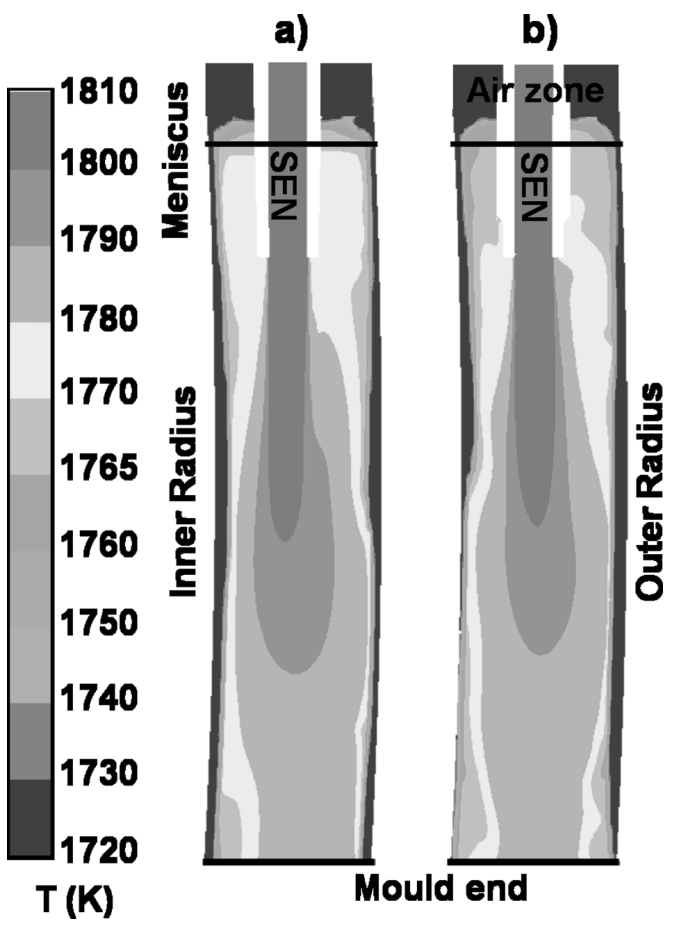

Fig. 8. Contours of temperature on the central-symmetric plane parallel to the mould radius: a) nozzle $\mathrm{S} 60$ and b) nozzle S73. $T_{S}=1724 \mathrm{~K}, T_{L}=1787.5 \mathrm{~K}$. 
nozzle S60 yields a uniform and thick shell in this plane which makes a contrast with the parallel plane to the mould radius where shell thinning effects are predicted. According with these results it can be said that a mould flux must be designed not only to respond the steel chemistry but to the nozzle design as well. It is inferred also that the nozzle design influences directly the fluid flow and the flux infiltration dynamics.

Figures 10(a)-10(c) show contours of the liquid fraction of steel and Figs. 10(e)-10(f) show the corresponding phase fractions contours of mould flux using nozzle S60 at three

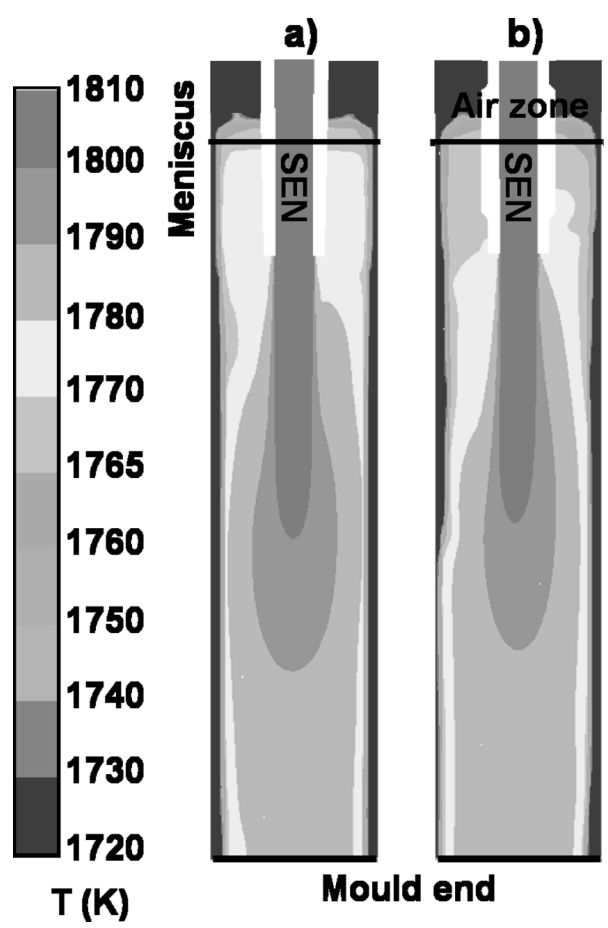

Fig. 9. Contours of temperature on the central-symmetric plane perpendicular to the mould radius: a) nozzle $\mathrm{S} 60$ and b) nozzle S73. $T_{S}=1724 \mathrm{~K}, T_{L}=1787.5 \mathrm{~K}$

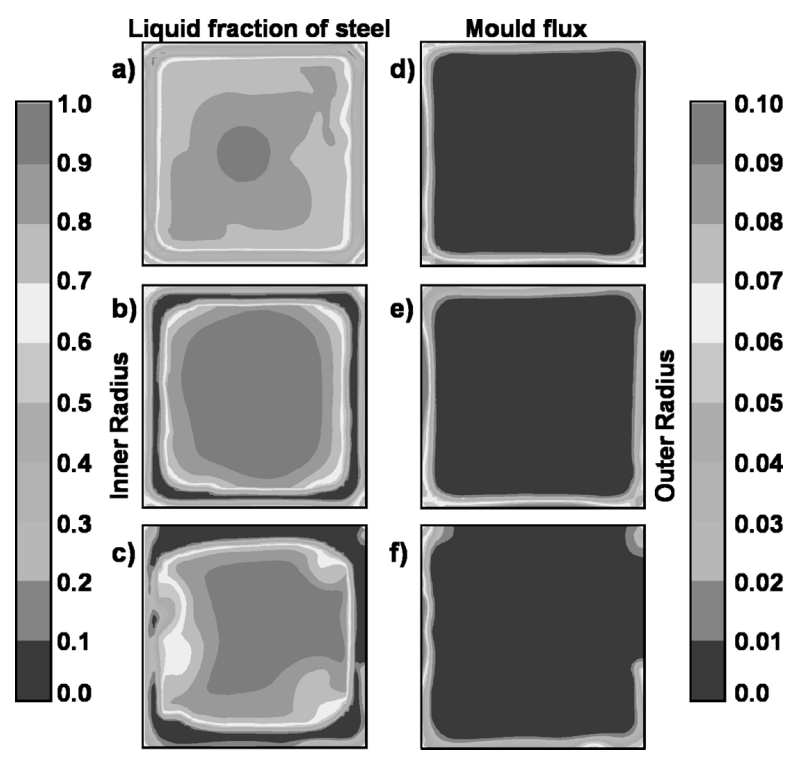

Fig. 10. Contours of the liquid fraction of steel and the mould flux using nozzle S60 at three horizontal planes: a) and d) at the tip of the nozzle, b) and e) at half of the mould length, and c) and f) at the mould end. horizontal planes located just at the tip of the nozzle, at half of the mould length and at the mould end. As is seen, the shell observes a uniform growth downstream the mould and only close to the mould end a small irregular growth is observed in the inner mould radius side. This shell thinning effect is originated by a hot stream coming from the jet transporting, by convection mechanisms, sensible heat to the inner strand surface. Intuitively it might be expected that the steel closer to the meniscus is hotter than that located in the middle position. However, these simulations demonstrate an opposite situation which is explained by the fact that the ascending melt is losing energy mainly by slow conduction transfer through the shell, flux layer and the mould wall in a region where the velocities are small. Meanwhile, at the intermediate plane, the penetration effect of the hot steel jet raises the temperature field in the region. It is important to notice that between the mould hot faces and the strand, Figs. 10(a)-10(e), there is an apparent remelting phenomenon of the shell; nevertheless, that is not the case. Actually, the phase contours of flux (Figs. 10(d)10(f)) indicate that those regions are filled with liquid flux giving the appearance of liquid steel. Those figures indicate that flux in the inner mould side has larger liquid fractions than the outer mould side. Figures 11(a)-11(f) show the same type of information that in Fig. 10, but for the case of using nozzle S73. Different to the precedent case here the shell yields a non-uniform growth along the mould downstream. Particularly, at the level of the intermediate plane there is a shell thinning effect originated by the recirculating flows located at both sides of the entry jet as is observed in Fig. 3(d). These effects are reflected with a stronger shell thinning at the mould end, Fig. 11(c); eventually, this small shell thickness in the inner mould radius would lead to a strand breakout. Figures 11(d)-11(f) show the phase contours of mould flux and their interpretation is the same as that provided to Figs. 10(d)-10(f), emphasizing the difficulties for an efficient flux infiltration.

The shell thickness (calculated using the average mushy

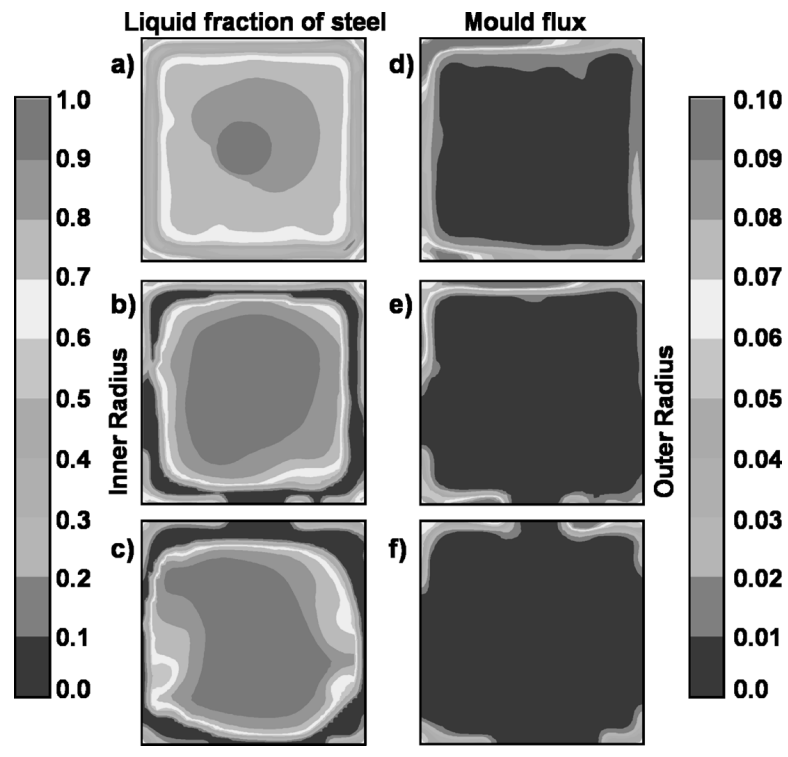

Fig. 11. Contours of the liquid fraction of steel and the mould flux using nozzle S73 at three horizontal planes: a) and d) at the tip of the nozzle, b) and e) at half of the mould length, and c) and f) at the mould end. 

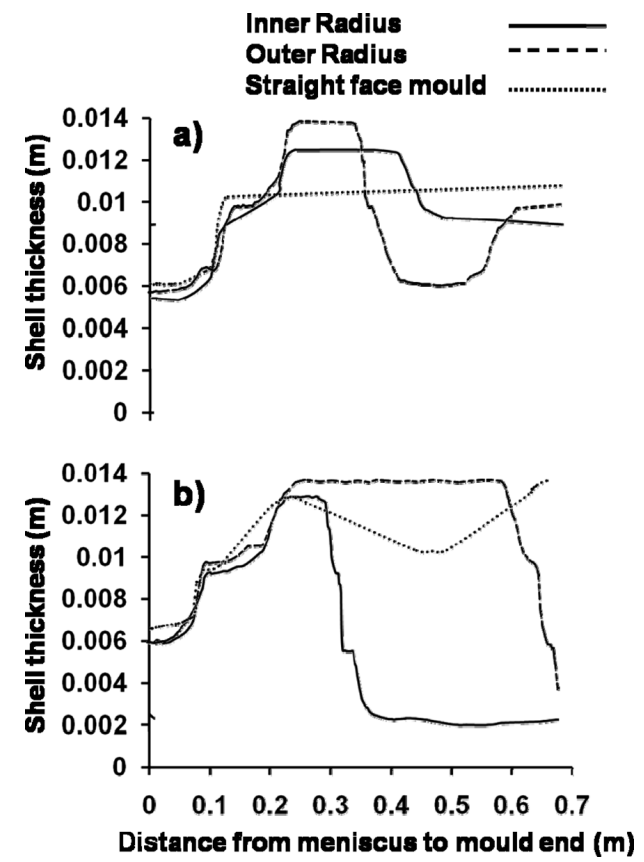

Fig. 12. Shell thickness along the mould height: a) nozzles S60 and b) nozzle S73.

zone temperature given by $\left.\left(T_{\mathrm{S}}+T_{\mathrm{L}}\right) / 2\right)$ along the mould height, from the meniscus level to the mould end, is plotted in Figs. 12(a) and 12(b) for nozzles S60 and S73, respectively. It is important to notice that using either of these two nozzles there is considerable shell growth at the meniscus level indicating that, at least at the meniscus, the shell strength must be high enough to resist well friction forces. Other observation is that both shells yield similar growth thicknesses until a level of $0.3 \mathrm{~m}$ below the meniscus for the both curved mould faces. At deeper levels the shell growth is completely different for both nozzles and, particularly, for the outer and the inner mould faces. For nozzle S60 at both radiuses the shell suffers severe thinning effects due to the existence of the recirculating flows described above. It is important to mention that the shell in the outer mould radius side suffers a severer thinning, but at the mould end the shell thicknesses for both radius faces are very similar. The shell thickness in the straight mould face remains approximately constant downstream the mould after the initial high shell growth at the meniscus level. A quite different shell thickness evolution is observed using nozzle S73. Indeed, the large recirculating flows in the middle and lower parts of the mould induce very strong shell thinning effects, affecting more severely the inner mould radius face which may lead to the existence of a strand breakout as has been pointed out above. The shell thickness in the straight mould face, after the initial high growth rate, suffers small shell thinning effects, but its thickness remains large all the way down the mould. These differences of shell thicknesses among all strand faces may be cause also of billet distortion in the zone of secondary cooling.

Another factor that is definitively influencing the shell growth, which depends also on fluid flow, is the flux infiltration patterns between the mould and the strand. Figures 13(a) and 13(b) show the infiltration patterns of the flux along the mould height using nozzles S60 and S73, respectively. It is evident that using nozzle S60 the flux infiltration

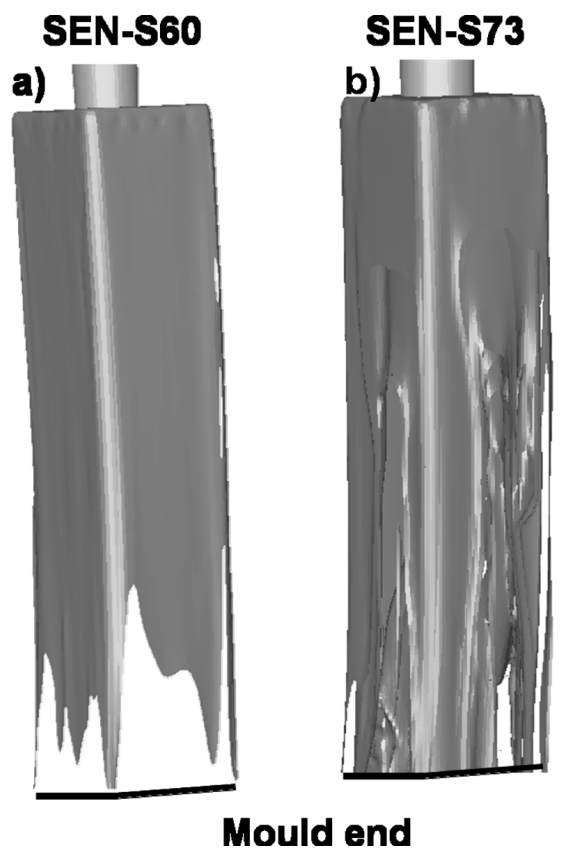

Fig. 13. $3 \mathrm{D}$ views of infiltration patterns of the flux along the mould height: a) nozzles S60 and b) nozzle S73.

is uniform from the meniscus level to the mould end. However, nozzle S73 yields an irregular infiltration especially in the last $2 / 3$ of the mould's working height. The explanation of these infiltration patterns is partially found in Figs. 10(d) and 11(d) for nozzles S60 and S73 in a plane located just at the level of their tips. In the first case the infiltration is uniform all around the mould faces, while in the second case flux infiltration is mainly through the upper mould corner in the inner radius side, leaving the outer mould radius side scarcer of flux. These results are not absolute in their prediction capacity as mould oscillation was not considered in the numerical simulations. Nevertheless, they indicate, qualitatively, that there is a direct relation between nozzle design and flux infiltration through the fluid flow pattern inside the mould, especially at the meniscus level. It is also necessary to underline that the flux infiltration patterns reported in Figs. 13(a) and 13(b) may change for better by the effects of mould oscillation.

\section{Conclusions}

A mathematical model including multiphase-fluid dynamics, heat transfer, steel solidification and flux infiltration was elaborated with the purpose to describe the effect of nozzle design on shell growth; the conclusions drawn from this study are as follows:

(1) Jet penetration is strongly influenced by buoyancy forces to the extent of exerting a strong brake effect. Simulation of hypothetical isothermal conditions allowed the evaluation of buoyancy forces to be around $1 / 4$ of the inertial forces during jet penetration.

(2) Flotation forces are larger in the outer and interior mould radius walls for nozzle S73, while for nozzle S60 buoyancy forces are larger in the upper and lower parts of the mould. These differences are induced by only minor differences of nozzle geometry due to the formation of rotational flows in the gap formed between the mould and the 
SEN walls.

(3) Nozzle geometry demonstrates to affect the fluid flow patterns, the shell growth along the entire interior mould surface, the heat flux distribution and the infiltration patterns of mould flux.

(4) It is suggested, from the results of the present investigation, that flux design must be based on steel chemistry and nozzle design as well.

\section{Acknowledgements}

The authors give the thanks to CoNaCyT for granted scholarships, to COFAA, SNI and EDI institutions for the permanent support to the Process Metallurgy Group at IPNESIQIE, Department of Metallurgy.

\section{Nomenclature}

$E: \quad$ Enthalpy $[\mathrm{J}]$

$f_{l}$ : Liquid fraction in the $q$-phase mushy zone

$g:$ Gravity force $\left[\mathrm{m} / \mathrm{s}^{2}\right]$

$K_{q}$ : Thermal conductivity $[\mathrm{W} / \mathrm{m} \mathrm{s}]$

$k$ : Turbulence kinetic energy $\left[\mathrm{m}^{2} / \mathrm{s}^{2}\right]$

$L$ : Characteristic length [m]

$L_{0}: \quad$ Distance from SEN tip to mould end [m]

$\dot{m}_{p q}, \dot{m}_{q p}: \quad$ Mass transfer from phase to phase

$p:$ Pressure $\left[\mathrm{N} / \mathrm{m}^{\mathrm{z}}\right]$

$p, q:$ Phases present at each cell

$S_{\alpha_{a}}$ : Source term for mass exchange

$S_{S}^{q}$ : Momentum sink due to the solidification

$S_{\sigma}:$ Source term due to the surface tension

$T$ : Temperature [K]

$T_{\text {liquidus }}, T_{\text {solidus }}: \quad$ Liquidus and solidus temperatures $[\mathrm{K}]$

$\vec{v}, \vec{u}: \quad$ Fluid velocity $[\mathrm{m} / \mathrm{s}]$

$U_{f}$ : Volume flux throught the face

$V: \quad$ Volume of cell $\left[\mathrm{m}^{3}\right]$

Greek symbols

$\alpha_{p, q}:$ Phase fraction

$\beta$ : Thermal expansion coefficient $[1 / \mathrm{T}]$

$\varepsilon$ : Turbulence dissipation rate $\left[\mathrm{m}^{2} / \mathrm{s}^{3}\right]$

$\rho_{\text {mix }}, \rho_{p, q}:$ Mixture and phase densities $\left[\mathrm{kg} / \mathrm{m}^{3}\right]$

$\mu_{\text {mix }}, \mu_{p, q}, \mu_{\text {flux }}$ : Mixture, phase and mould powder viscosities $\left[\mathrm{N}-\mathrm{s} / \mathrm{m}^{2}\right]$

\section{REFERENCES}

1) L. K. Chiang: 13th PTD Conf. Proc., (1995), 293.

2) M. El-Bealy and H. Fredriksson: Metall. Mater. Trans. B, 27 (1996), 999.

3) A. Yamauchi, K. Sorimachi and T. Sakuraya: Proc. Fourth Int. Conf. on Metall. Slags and Fluxes, ISIJ, Tokyo, (1992), 415.

4) X. Liu and M. Zhu: ISIJ Int., 46 (2006), 1652.

5) J. Savage and W. H. Pritchard: J. Iron Steel Inst., 178 (1954), 269.

6) M. R. Aboutalebi, M. Hasan and R. I. Guthrie: Metall. Mater. Trans. $B, 26$ (1995), 731.

7) X. K. Lan, J. M. Khodadadi and F. Shen: Metall. Mater. Trans. B, 28 (1997), 321
8) J. Szekely and R. T. Yadoya: Metall. Mater. Trans. B, 3 (1972), 2673.

9) J. Szekely and R. T. Yadoya: Metall. Mater. Trans. B, 4 (1973), 1379.

10) C. Chow and I. V. Samaresekera: Ironmaking Steelmaking, 29 (2002), 53.

11) C. Chow, I. V. Samarasekera, B. N. Walker and G. Lockhart: Ironmaking Steelmaking, 29 (2002), 61.

12) M. Kawamoto, Y. Tsukaguchi, N. Nishida, T. Kanazawa and S. Hiraki: ISIJ Int., 37 (1997), 134.

13) J. W. Cho, T. Emi, H. Shibata and M. Suzuki: ISIJ Int., 38 (1998), 834.

14) J. Cho, H. Shibata, T. Emi and M. Suzuki: ISIJ Int., 38 (1998), 268.

15) J. Cho, H. Shibata, T. Emi and M. Suzuki: ISIJ Int., 38 (1998), 440.

16) A. Yamauchi, T. Emi and S. Seetharaman: ISIJ Int., 42 (2002), 1084.

17) K. Okazawa, T. Kajitani, W. Yamada and H. Yamamura: ISIJ Int., 46 (2006), 226.

18) K. Okazawa, T. Kajitani, W. Yamada and H. Yamamura: ISIJ Int., 46 (2006), 234.

19) V. Ludlow, S. Riaz, R. Striedinger, K. Sterken, R. Falesi, C. Mapelli, R. de Miranda and G. Gerbino: Technical Steel Research, European Commission, Improvement to Billet Quality, 45 (2007), 213.

20) J. P. Suni and H. Henein: Metall. Mater. Trans. B, 27 (1996), 1045

21) B. Zhao, B. G. Thomas, S. P. Vanka and R. J. O'Malley: Metall. Mater. Trans. B, 36 (2005), 801.

22) R. D. Morales and P. Ramirez-Lopez: Proc. AISTech Conf., 20 (2006).

23) R. D. Morales: Proc. 15th Steelmaking Conf., Instituto Argentino de Siderurgia, Sn. Nicolás Argentina, (2005), 253.

24) E. Torres-Alonso, R. D. Morales, S. Garcia-Hernandez, A. NajeraBastida and A. Sandoval-Ramos: Metall. Mater. Trans. B, 39 (2008), 840.

$25)$ B. G. Thomas, S. Vanka and S. Q. Yang: Metall. Mater. Trans. B, 35 (2004), 685.

26) S. B. Pope: Turbulent Flows, Cornell University, Cambridge University Press, (2000), 83.

27) Fluent Documentation: Fluent Inc., Lebanon NH, USA, (2007).

28) J. Liow, L. Rudman and P. Liovic: ISIJ Int., 41 (2001), 225.

29) R. B. Bird, W. E. Stewart and E. N. Lightfoot: Transport Phenomena, Wiley-Toppan, New York, (1960), 155.

30) D. C. Wilcox: Turbulence Modeling for CFD, DCW Industries, La Cañada CA, New York, (2000), 123.

31) C. A. M. Pinheiro, I. V. Samarasekera, J. K. Brimacombe, B. Howes and O. Gussias: Ironmaking Steelmaking, 27 (2000), 144.

32) O. D. Kwon, J. Choi, I. R. Lee, J. W. Kim, K. H. Moon and Y. K. Shin: Steelmaking Conf. Proc., ISS, Warrendale, PA, (1991), 561.

33) K. Nakajima, H. Hiraki, T. Kanazawa and T. Murakami: CAMP-ISIJ, 5 (1992), 1221.

34) M. M. Wolf: Trans. Iron Steel Inst. Jpn., 20 (1980), 718.

35) S. Ogibayashi: Nippon Steel Tech. Rep., 34 (1987), 1.

36) A.S. Normanton, V. Ludlow, B. Harris, M. Hecht, C. A. Dacker, A. Di Donato and T. Sohlgren: Mould Powder Consumption, Melting and Lubrication and their Effects on Mould Heat Transfer and Subsequent Surface Quality of Continuously Cast Slab, Technical Steel Research, European Commission, (2005), 116.

37) W. Kim, J. Choi, O. C. Kwon, R. I. Lee, Y. K. Shin and J. S. Park: Proc. of 4th Int. Conf. on Molten Slags, Fluxes and Salts, The Metallurgical Soc. of AIWE, Warrendale, PA, (1992), 468.

38) K. Koyama, K. Nagano, Y. Nagano and T. Nakano: Nippon Steel Tech.l Rep., 34 (1987), 41.

39) K. C. Mills and B. J. Keene: Int. Mater. Rev., 32 (1987), No. 2, 229.

40) T. Iida, H. Sakai, Y. Kita and K. Shigeno: ISIJ Int., 40 (2000), S110.

41) S. Joo, J. W. Han and R. I. L. Guthrie: Metall. Mater. Trans. B, 24 (1993), 767.

42) J. M. Cabrera-Marrero, V. Carreño-Galindo and R. D. Morales: ISIJ Int., 38 (1998), 822. 